\title{
Trans-ethyl methyl ether in space
}

\section{A new look at a complex molecule in selected hot core regions ${ }^{\star}$}

\author{
G. W. Fuchs ${ }^{1,2}$, U. Fuchs ${ }^{3}$, T. F. Giesen ${ }^{3}$, and F. Wyrowski ${ }^{4}$ \\ 1 Department of Chemistry, UC Berkeley, Berkeley, CA 94720, USA \\ 2 Raymond and Beverly Sackler Laboratory for Astrophysics, Leiden Observatory, Leiden University, Postbus 9513 , 2300 RA, Leiden, \\ The Netherlands \\ e-mail: fuchs@strw.leidenuniv.nl \\ 3 I. Physikalisches Institut, Universität zu Köln, Zülpicher Str. 77, 50937 Köln, Germany \\ e-mail: ufuchs@ph1.uni-koeln.de,giesen@ph1.uni-koeln.de \\ ${ }^{4}$ Max-Planck-Institut für Radioastronomie, Auf dem Hügel 69, 53121 Bonn, Germany \\ e-mail: wyrowski@mpifr-bonn.mpg.de
}

Received 9 June 2005 / Accepted 22 August 2005

\section{ABSTRACT}

An extensive search for the complex molecule trans-ethyl methyl ether towards several hot core regions has been performed. Using the IRAM $30 \mathrm{~m}$ telescope and the SEST $15 \mathrm{~m}$ we looked at several frequencies where trans-ethyl methyl ether has strong transitions, as well as lines which are particularly sensitive to the physical conditions in which the molecule can be found. We included G34.26, NGC 6334(I), Orion KL, and W51e2 which have previously been proven to have a rich chemistry of complex molecules. Our observations cannot confirm the tentative Orion KL detection made by Charnley et al. (2001) within their stated column density limits, but we confirm the existence of the trans-ethyl methyl ether towards W51e2 with a column density of $2 \times 10^{14} \mathrm{~cm}^{-2}$. The dimethyl ether/methanol ratio of 0.6 as well as the newly found ethyl methyl ether/ethanol ratio of 0.13 indicate relative high abundances of ethers toward W51e2. Furthermore, the observation of ethyl methyl ether also confirms the importance of ethanol as a grain mantle constituent. We present new upper limits of around $8 \times 10^{13} \mathrm{~cm}^{-2}$ for the column densities of the molecule toward Orion KL, G34.26, NGC 6334(I) and estimate the column density towards SgrB2(N) to be of the same order. The W51e2 observations are discussed in more detail.

Key words. line: identification - astrochemistry - radio lines: ISM - ISM: clouds - ISM: molecules

\section{Introduction}

Various large and complex molecules of prebiotic importance have been found as constituents of dense interstellar clouds but their detection remains difficult and some of them doubtful (Snyder et al. 2005). Fortunately, space offers many places with a rich chemistry and hot molecular cores (HMCs) are prime targets for such investigations. However, the spectra towards hot cores often reveal a high line density and thus proper line assignments are difficult and have to be viewed with a critical eye. The ethyl methyl ether $\left(\mathrm{CH}_{3} \mathrm{OC}_{2} \mathrm{H}_{5}\right)$ is an asymmetric top molecule with two methyl groups acting as internal rotors. Ethyl methyl ether (EME) has two conformers where the transEME is lower in energy than the gauche-EME by $550 \mathrm{~cm}^{-1}$ (Durig et al. 2002) and thus favored as an astrophysically detectable species. We searched for several transitions of transEME to confirm the tentative detection of this molecule by

$\star$ Table 5 is only available in electronic form at http://www. edpsciences.org
Charnley et al. (2001). A positive result means the detection of one of the biggest molecules in the interstellar medium (ISM). Charnley et al. (2001) observed a single line in W51 e1/e2 and Orion $\mathrm{KL}$ at $160.1 \mathrm{GHz}$ and another line in SgrB2(N) at $79.6 \mathrm{GHz}$ which they assigned to trans-ethyl methyl ether. Based on these isolated measurements, Charnley et al. (2001) estimate the column density of EME to be in the range of $10^{14}-10^{15} \mathrm{~cm}^{-2}$ in Sgr B2(N). Thus, assuming a hydrogen column density of $10^{24} \mathrm{~cm}^{-2}$ gives a fractional abundance of $10^{-10}-10^{-9}$. For W51, they estimate EME to have an abundance of a few times $10^{-10}$. Furthermore, they conclude that the emission of EME closely follows that of methanol, as expected if these molecules are chemically linked. Charnley et al. (1995) suggest the following production mechanism for EME in hot cores where temperatures can rise to $100-300 \mathrm{~K}$. Icy mantles which are thought to contain alcohols (e.g. methanol, ethanol) evaporate from dusty grains, e.g. Millar \& Hatchell (1998), the alcohols themselves are thought to be produced via surface reactions starting from the precursor $\mathrm{CO}$. Once the 


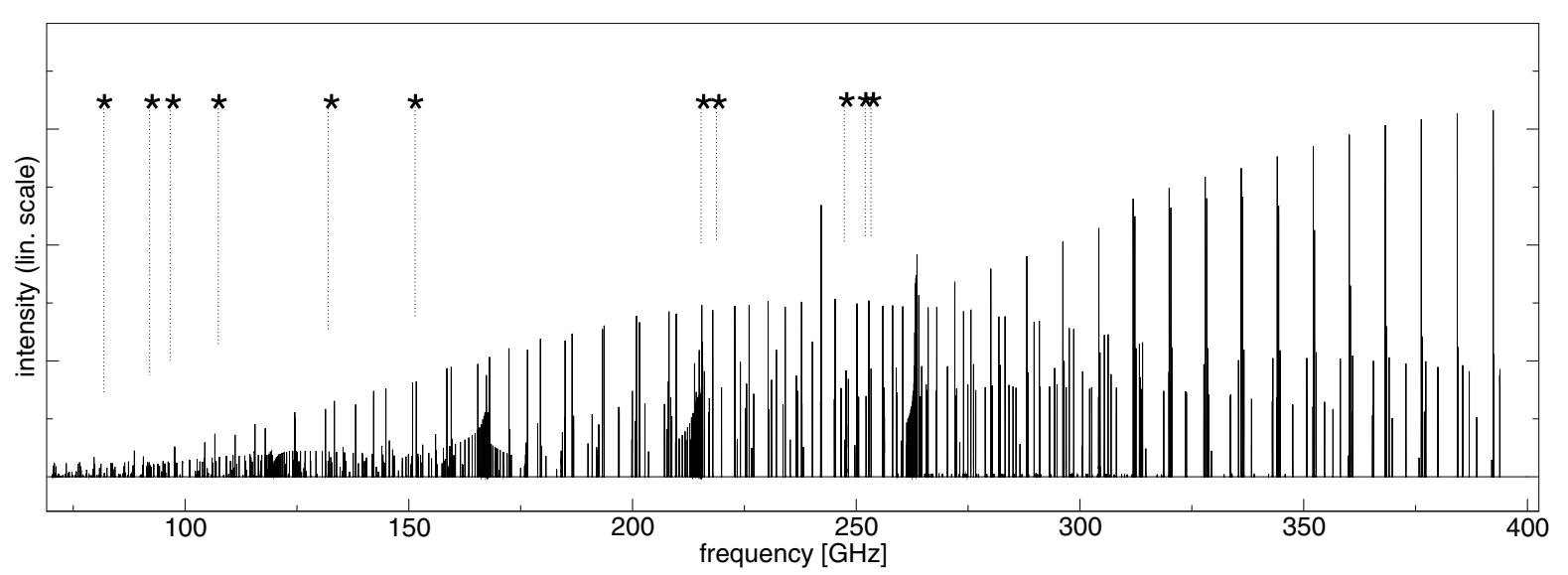

Fig. 1. Stick spectrum of EME at a rotational temperature of $130 \mathrm{~K}$ which is typical for complex molecules in hot core regions. EME has a dense spectrum with many characteristic features. The frequencies are taken from Fuchs et al. (2003). The ( $\star$ ) indicate our chosen frequency regions for the W51e2 obseravtions. The intense line at $237 \mathrm{GHz}$ was not selected because of a blending line at the same frequency.

Table 1. Astronomical sources.

\begin{tabular}{lcrcrc}
\hline \hline Source & RA & Dec & Eq. & $\begin{array}{r}\text { LSR } \\
\left(\mathrm{km} \mathrm{s}^{-1}\right)\end{array}$ & telescope \\
\hline G34.26 & 185318.496 & 011458.66 & 2000 & +60.0 & IRAM 30 m \\
NGC 6334 I & 171732.300 & -354404.00 & 1950 & -8.0 & SEST 15 m \\
Orion KL & 053514.171 & -052223.10 & 2000 & +8.8 & IRAM 30 m \\
W51 e2 & 192343.959 & 143034.55 & 2000 & +55.0 & IRAM 30 m \\
\hline
\end{tabular}

mantles evaporate the alcohols can be converted into ethers and other species. The production of ethers is thought to happen via ion-molecule reactions ${ }^{1}$ (i), methylisation of the protonated species $^{2}$ (ii) and dissociative recombination with electrons (iii):

$$
\begin{aligned}
& \text { i) } \mathrm{C}_{2} \mathrm{H}_{5} \mathrm{OH} \underset{\mathrm{HCO}^{+}}{\stackrel{\mathrm{H}_{3} \mathrm{O}^{+}}{\longrightarrow}} \mathrm{C}_{2} \mathrm{H}_{5} \mathrm{OH}_{2}^{+} \\
& \text {ii) } \mathrm{C}_{2} \mathrm{H}_{5} \mathrm{OH}_{2}^{+} \underset{\mathrm{CH}_{3} \mathrm{OH}}{\longrightarrow} \mathrm{CH}_{3} \mathrm{OC}_{2} \mathrm{H}_{6}^{+} \\
& \text {iii) } \mathrm{CH}_{3} \mathrm{OC}_{2} \mathrm{H}_{6}^{+} \stackrel{\mathrm{e}^{-}}{\longrightarrow} \mathrm{CH}_{3} \mathrm{OC}_{2} \mathrm{H}_{5}
\end{aligned}
$$

In hot cores saturated species are the dominant constituents. For instance, methanol $\mathrm{CH}_{3} \mathrm{OH}$ is highly abundant and dimethyl ether $\left(\mathrm{CH}_{3}\right)_{2} \mathrm{O}$ and ethanol $\mathrm{C}_{2} \mathrm{H}_{5} \mathrm{OH}$ are seen only in hot cores (Herbst 2001). Charnley et al. (1995) mention in their work that dimethyl ether, diethyl ether $\left(\mathrm{C}_{2} \mathrm{H}_{5}\right)_{2} \mathrm{O}$, and transEME should be present in detectable quantities within cores rich in ethanol and methanol. Furthermore, a detection of either EME or diethyl ether would confirm the importance of ethanol as a grain mantle constituent.

\section{EME spectrum and observations}

Only two investigations on the laboratory rotational spectrum of EME have been reported in the literature. The more recent measurements by Fuchs et al. (2003) from $55 \mathrm{GHz}$ to $350 \mathrm{GHz}$ also include the previously published data below $40 \mathrm{GHz}$ by Hayashi \& Kuwada (1975) in their analysis. Reliable frequency predictions up to $400 \mathrm{GHz}$ are now available. Since EME consists of two methyl groups designated as internal rotors, the

\footnotetext{
1 See Mackay et al. (1979); Bohme et al. (1979).

2 See Karpas \& Meot-Ner (1989).
}

laboratory spectra reveal extra line splittings which are not necessarily seen in space due to larger line widths in the HMC environment. The spectroscopic aspects of ethyl methyl ether in the mm-wave region are described in our earlier publications (see Fuchs et al. 2003; Fuchs 2003, and references therein). EME is an asymmetric top molecule which has weak $a$-type transitions and fairly strong $b$-type transitions above $100 \mathrm{GHz}$ which in theory split into quintets caused by internal torsion. Laboratory measurements can resolve only doublets and quartets with splittings mostly between 0.8 and $2 \mathrm{MHz}$ in our examined frequency ranges. However, none of the astronomically observed lines is torsionally resolved. Figure 1 shows the complexity of the EME spectrum up to $400 \mathrm{GHz}$ with its characteristic features. The IRAM $30 \mathrm{~m}$ telescope at Pico Veleta, Spain, has been used during several days in Sept. 2002 and July 2003 and the SEST 15 m telescope at La Silla, Chile, in March 2003. The hot core regions of G34.26, NGC 6334I, Orion KL and W51e2 were observed, see Table 1. Rotational transitions of EME have been searched in the $1 \mathrm{~mm}-, 2 \mathrm{~mm}-$, and $3 \mathrm{~mm}$-range. Depending on the source, between 5 and 11 frequency settings have been used, see the online table for observational details. Typical frequency resolutions were $0.3,1$ and $1.25 \mathrm{MHz}$, typical bandwidths between 490 and $1020 \mathrm{MHz}$ and rms noise levels between $0.01 \mathrm{~K}$ at $81 \mathrm{GHz}$ and $0.02-0.05 \mathrm{~K}$ at $245 \mathrm{GHz}$. The bands were chosen to allow for the observation of $\mathrm{CH}_{3} \mathrm{OH}$ (a-type), $\mathrm{C}_{2} \mathrm{H}_{5} \mathrm{OH}$ and $\mathrm{CH}_{3} \mathrm{OCH}_{3}$ transitions as well. At least 5 strong lines have been measured from each of these species, except for $\mathrm{CH}_{3} \mathrm{OH}$ in Orion $\mathrm{KL}$ where only three transitions have been observed.

The intensities are measured in $T_{\mathrm{A}}^{*}$ the effective antenna temperature corrected for spillover losses and atmospheric 
attenuation, and are then converted to $T_{\mathrm{mb}}=T_{\mathrm{A}}^{*} / \rho$ using the beam efficiencies $\rho$ of the telescopes at the given frequencies.

All sources were examined using long integration times up to $220 \mathrm{~min}$ on+off time, elevations greater $40^{\circ}$ and under good atmospheric weather conditions.

\section{Source selection}

A selection of previous work on the sources is given below. The authors do not intend to give a review of these sources but rather focus on contributions relevant for the EME analysis.

G34.3+0.15 has been surveyed by MacDonald et al. (1996) and Thompson et al. (1999) in the 330-360 GHz region. Nomura \& Millar (2004) examined the chemical structure of this region and gave an overview of the observed species and their abundances along with some comparisons to their model predictions. Single molecule investigations like ethanol have been performed by Millar et al. (1995). Nummelin et al. (1998b) examined $\mathrm{CH}_{3} \mathrm{CHO}$ and $\mathrm{c}-\mathrm{C}_{2} \mathrm{H}_{4} \mathrm{O}$ but also gave abundances for methanol, ethanol and dimethyl ether (DME). Heaton et al. (1989) mapped the G34.3 region using the $\mathrm{NH}_{3}(3,3)$ emission and determined a size of $3^{\prime \prime} \times 1^{\prime \prime}$. 2 . The column density of $\mathrm{H}_{2}$ towards $\mathrm{G} 34.26$ has been estimated by Millar et al. (1995) to be $N_{\mathrm{t}}\left(\mathrm{H}_{2}\right)=5.3 \times 10^{23} \mathrm{~cm}^{-2}$. Nummelin et al. (1998b) published a similar result of $N_{\mathrm{t}}\left(\mathrm{H}_{2}\right)=3.0 \times$ $10^{23} \mathrm{~cm}^{-2}$ for a $20^{\prime \prime}$ source size.

NGC 6334I (NGC 6334F, G351.41+0.64) has been mapped in the continuum by Sandell (2000). McCutcheon et al. (2000) took several spectra in the range between 334 and $348 \mathrm{GHz}$ using the JCMT. They also mapped the region in $\mathrm{CH}_{3} \mathrm{OCH}_{3}$ emission. Nummelin et al. (1998b) estimated the abundances of ethanol, methanol and DME in NGC 6334I and a hydrogen column density of $N_{\mathrm{t}}\left(\mathrm{H}_{2}\right)=2.0 \times 10^{23} \mathrm{~cm}^{-2}$ within $20^{\prime \prime}$. Cheung et al. (1978) estimate $N_{\mathrm{t}}\left(\mathrm{H}_{2}\right) \approx 10^{24} \mathrm{~cm}^{-2}$.

Orion KL is a well studied object in the sky. Turner (1989, 1991) performed a line survey between 70 and $115 \mathrm{GHz}$, Lee \& Cho (2002) presented line spectra between 159.7 to $164.7 \mathrm{GHz}$ and Sutton et al. (1985) scanned the spectral region between 215 and $247 \mathrm{GHz}$. Blake et al. (1987) studied the chemical composition of OMC-1 in the $230 \mathrm{GHz}$ atmospheric window. They estimate the hydrogen column density to be $N_{\mathrm{t}}\left(\mathrm{H}_{2}\right)=$ $1.0 \times 10^{23} \mathrm{~cm}^{-2}$ for the hot core. The region between 330 to $355 \mathrm{GHz}$ was examined by Sutton et al. (1991), and Schilke et al. (1997) performed a survey from $325 \mathrm{GHz}$ to $360 \mathrm{GHz}$ (see also references therein). The distribution of some key molecules for the EME analysis has been presented by Sutton et al. (1995). Caselli et al. (1993) applied a dynamical-chemical model which included abundances of many observed species.

The W51 molecular cloud is described in Carpenter \& Sanders (1998). The chemistry of the W51e 2 region has been investigated by several groups. For example, Zhang et al. (1998) has done $\mathrm{CH}_{3} \mathrm{CN}$ and $\mathrm{CS}$ (3-2) observations, Remijan et al. $(2004,2002)$ investigated $\mathrm{CH}_{3} \mathrm{CN}$ and $\mathrm{CH}_{3} \mathrm{COOH}$, Liu et al. (2001) looked for $\mathrm{HCOOH}$ in this source and Kuan et al. (2004) searched for several molecules of potential prebiotic importance. The hydrogen column density $3.6 \times 10^{23} \mathrm{~cm}^{-2}$ (Ikeda et al. 2001) is based on $\mathrm{C}^{18} \mathrm{O}$ data from Schloerb et al. (1987).

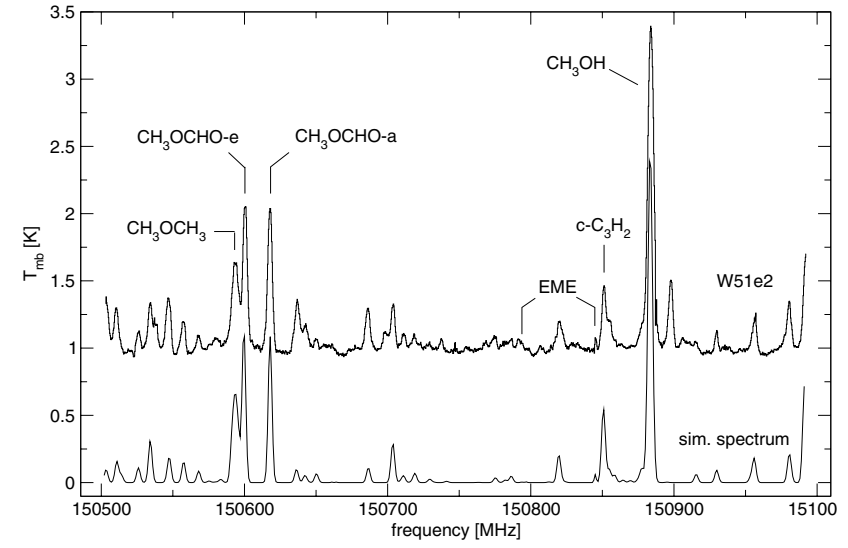

Fig. 2. Observed spectrum of $\mathrm{W} 51 \mathrm{e} 2$ at $151 \mathrm{GHz}$ (upper) and simulated spectrum using myXCLASS (lower) including $\mathrm{C}_{2} \mathrm{H}_{5} \mathrm{OCH}_{3}, \mathrm{C}_{2} \mathrm{H}_{5} \mathrm{OOCH}, \quad \mathrm{CH}_{3} \mathrm{CH}_{3} \mathrm{CO}, \mathrm{a}-\left(\mathrm{CH}_{2} \mathrm{OH}\right)_{2}, \quad c-\mathrm{C}_{2} \mathrm{H}_{4} \mathrm{O}$, $\mathrm{C}_{2} \mathrm{H}_{5} \mathrm{OH}, \mathrm{CH}_{3} \mathrm{OCH}_{3}, \mathrm{CH}_{3} \mathrm{CHO}-\mathrm{e}, \mathrm{CH}_{3} \mathrm{OH}, \mathrm{C}_{2} \mathrm{H}_{5} \mathrm{OH}, \mathrm{CH}_{3} \mathrm{OCHO}-\mathrm{e}$, and $\mathrm{CH}_{3} \mathrm{OCHO}-\mathrm{a}$.

Also the SgrB2 region has been investigated by many groups. It is not part of our own observations but since Charnley et al. (2001) detected one line at an EME transition frequency we use the published data to estimate the column density of EME in Sect. 6. A spectral line survey from 70 and $150 \mathrm{GHz}$ has been performed by Cummins et al. (1986), and from 70 to $115 \mathrm{GHz}$ by Turner $(1989,1991)$. A further $3 \mathrm{~mm}$ spectral line survey has been carried out by Friedel et al. (2004) using the NRAO12 $\mathrm{m}$ and the BIMA array telescopes. Nummelin et al. (1998a) extended these observations to frequencies between 218 and $263 \mathrm{GHz}$. Selected molecules, like the oxygen bearing $\mathrm{CH}_{3} \mathrm{COOH}$, have been studied by Remijan et al. (2002), and $\mathrm{NH}_{3}$ by Hüttemeister et al. (1993) with comparisons between several sources including those studied here. Martín-Pintado et al. (1990) estimated $N_{\mathrm{t}}\left(\mathrm{H}_{2}\right)=5.0 \times 10^{24} \mathrm{~cm}^{-2}$ to be the hydrogen column density ${ }^{3}$.

Ikeda et al. (2001, 2002) gave temperatures and abundances of methanol, ethanol and in most cases also for DME for all above mentioned sources. Table 2 summerizes the $\mathrm{CH}_{3} \mathrm{OH}$, $\mathrm{C}_{2} \mathrm{H}_{5} \mathrm{OH}, \mathrm{CH}_{3} \mathrm{OCH}_{3}$ and $\mathrm{C}_{2} \mathrm{H}_{5} \mathrm{CH}_{3}$ abundances including our latest results.

\section{Data analysis method}

For the analysis of the observed lines we used the Grenoble Image and Line Data Analysis Software GILDAS ${ }^{4}$ and in addition the myXCLASS code written by Peter Schilke which is backed by a database of astrophysically important molecules, including the EME data. myXCLASS can simulate the spectra of many molecules at a time, including their line profiles within the GILDAS environment and has restricted fitting capabilities. Figure 2 shows the observed spectrum of W51e 2 at $151 \mathrm{GHz}$ and the synthetic spectrum calculated by myXCLASS assuming optically thin lines where for each molecule the excitation

\footnotetext{
${ }^{3}$ Note, Charnley et al. (2001) assume $N_{\mathrm{H}_{2}}=1.0 \times 10^{24} \mathrm{~cm}^{-2}$.

${ }^{4}$ See http://www.iram.fr/IRAMFR/GILDAS
} 
Table 2. Rotational temperatures, column densities and fractional abundances $X$ relative to $\mathrm{H}_{2}$ of $\mathrm{CH}_{3} \mathrm{OH}, \mathrm{C}_{2} \mathrm{H}_{5} \mathrm{OH}_{2} \mathrm{CH}_{3} \mathrm{OCH}_{3}$ and $\mathrm{C}_{2} \mathrm{H}_{5} \mathrm{OCH}_{3}$ (EME) from our and other selected works.

\begin{tabular}{|c|c|c|c|c|c|c|}
\hline source & molecules & & $T_{\text {rot }}[\mathrm{K}]$ & $N_{\mathrm{t}}\left[\mathrm{cm}^{-2}\right]$ & $X^{a}$ & Reference \\
\hline \multicolumn{7}{|c|}{ G34.26 } \\
\hline & \multirow[t]{5}{*}{$\mathrm{CH}_{3} \mathrm{OH}$} & $a$-type & $368 \pm 16$ & $(1.8 \pm 0.2) \times 10^{16}$ & $4.5 \times 10^{-8}$ & MacDonald et al. (1996) \\
\hline & & & $368 \pm 16$ & $(1.6 \pm 0.2) \times 10^{16}$ & $4 \times 10^{-8}$ & Thompson et al. (1999) \\
\hline & & $b$-type & $336 \pm 14$ & $(1.9 \pm 0.1) \times 10^{16}$ & $4.8 \times 10^{-8}$ & MacDonald et al. (1996) \\
\hline & & $a+b$ type & $96 \pm 17$ & $(2.6 \pm 1.4) \times 10^{16}$ & $6.5 \times 10^{-8}$ & Ikeda et al. (2002) \\
\hline & & $a$-type & $140 \pm 14$ & $2.2_{-0.4}^{+4.7} \times 10^{16}$ & $5.5 \times 10^{-8}$ & this work \\
\hline & \multirow[t]{3}{*}{$\mathrm{C}_{2} \mathrm{H}_{5} \mathrm{OH}$} & & $94 \pm 27$ & $(3.5 \pm 2.0) \times 10^{15}$ & $8.8 \times 10^{-9}$ & MacDonald et al. (1996) \\
\hline & & & $75 \pm 37$ & $(1.7 \pm 2.1) \times 10^{15}$ & $4.3 \times 10^{-9}$ & Ikeda et al. (2002) \\
\hline & & & $152 \pm 66$ & $6.0_{-3.5}^{+8.4} \times 10^{14}$ & $1.5 \times 10^{-9}$ & this work \\
\hline & \multirow[t]{2}{*}{$\mathrm{CH}_{3} \mathrm{OCH}_{3}$} & & $137 \pm 32$ & $(3.7 \pm 1.8) \times 10^{15}$ & $9.3 \times 10^{-9}$ & Ikeda et al. (2002) \\
\hline & & & $146 \pm 38$ & $3.5_{-1.2}^{+1.8} \times 10^{15}$ & $8.8 \times 10^{-9}$ & this work \\
\hline & $\mathrm{C}_{2} \mathrm{H}_{5} \mathrm{OCH}_{3}$ & & $100-150$ & $<7 \times 10^{13}$ & $<1.8 \times 10^{-10}$ & this work \\
\hline \multicolumn{7}{|c|}{ NGC 6334 I } \\
\hline & \multirow[t]{2}{*}{$\mathrm{CH}_{3} \mathrm{OH}$} & & $79_{-8}^{+21}$ & $3.1_{-1.0}^{+0.8} \times 10^{16}$ & $1.6 \times 10^{-7}$ & Nummelin et al. (1998b) \\
\hline & & & $66 \pm 11$ & $1.2_{-1.2}^{+1.9} \times 10^{16}$ & $6.0 \times 10^{-8}$ & this work \\
\hline & \multirow[t]{2}{*}{$\mathrm{C}_{2} \mathrm{H}_{5} \mathrm{OH}$} & & $94_{-20}^{+44}$ & $1.4_{-0.3}^{+0.5} \times 10^{15}$ & $7.0 \times 10^{-9}$ & Nummelin et al. (1998b) \\
\hline & & & $120 \pm 44$ & $4.0_{-0.9}^{+1.2} \times 10^{14}$ & $2.0 \times 10^{-9}$ & this work \\
\hline & \multirow[t]{2}{*}{$\mathrm{CH}_{3} \mathrm{OCH}_{3}$} & & $20 / 440$ & $3.5 \times 10^{15} / 1.3 \times 10^{16}$ & $4.1 \times 10^{-8}$ & Nummelin et al. (1998b) \\
\hline & & & $119 \pm 39$ & $2.3_{-1.0}^{+1.8} \times 10^{15}$ & $1.2 \times 10^{-8}$ & this work \\
\hline & $\mathrm{C}_{2} \mathrm{H}_{5} \mathrm{OCH}_{3}$ & & $50-150$ & $<8 \times 10^{13}$ & $<4 \times 10^{-10}$ & this work \\
\hline \multicolumn{7}{|c|}{ Orion KL } \\
\hline & \multirow[t]{5}{*}{$\mathrm{CH}_{3} \mathrm{OH}$} & & $120-140$ & $5 \times 10^{16}$ & $5 \times 10^{-7}$ & Sutton et al. (1985) \\
\hline & & & 140 & $4.5 \times 10^{16}$ & $4.5 \times 10^{-7}$ & Turner (1991) (Onsala) \\
\hline & & & $192_{-16}^{+18}$ & $(1.6 \pm 0.2) \times 10^{16}$ & $1.6 \times 10^{-7}$ & Turner (1991) (NRAO) \\
\hline & & & $>200$ & $2.5-30 \times 10^{16}$ & $1.6 \times 10^{-6}$ & Sutton et al. (1995) \\
\hline & & & $120-200$ & $4-8 \times 10^{16}$ & $6 \times 10^{-7}$ & this work \\
\hline & \multirow[t]{2}{*}{$\mathrm{C}_{2} \mathrm{H}_{5} \mathrm{OH}$} & & $216_{-105}^{+3600}$ & $6.6_{-2.5}^{+4.1} \times 10^{15}$ & $6.6 \times 10^{-8}$ & Turner (1991) \\
\hline & & & $289 \pm 330$ & $4.8_{-4.2}^{+35} \times 10^{14}$ & $4.8 \times 10^{-9}$ & this work ${ }^{c}$ \\
\hline & \multirow[t]{6}{*}{$\mathrm{CH}_{3} \mathrm{OCH}_{3}$} & & 75 & $2.5 \times 10^{15}$ & $2.5 \times 10^{-8}$ & Johansson et al. (1984) \\
\hline & & & 63 & $3.0 \times 10^{15}$ & $3.0 \times 10^{-8}$ & Blake et al. (1986) \\
\hline & & & $91_{-19}^{+34}$ & $1.3_{-0.1}^{+0.3} \times 10^{15}$ & $1.3 \times 10^{-8}$ & Turner (1991) \\
\hline & & & 125 & $\sim 3 \times 10^{15}$ & $3.0 \times 10^{-8}$ & Sutton et al. (1995) \\
\hline & & & $197.4_{-62}^{+165}$ & $1.1_{-0.6}^{+2.5} \times 10^{16}$ & $1.1 \times 10^{-7}$ & Lee \& Cho (2002) \\
\hline & & & $126 \pm 43$ & $4.6_{-1.8}^{+3.1} \times 10^{15}$ & $4.6 \times 10^{-8}$ & this work \\
\hline & $\mathrm{C}_{2} \mathrm{H}_{5} \mathrm{OCH}_{3}$ & & $100-150$ & $<7 \times 10^{13}$ & $<7 \times 10^{-10}$ & this work \\
\hline \multicolumn{7}{|c|}{$\operatorname{SgrB} 2(\mathrm{~N})$} \\
\hline & \multirow[t]{4}{*}{$\mathrm{CH}_{3} \mathrm{OH}^{d}$} & I & $49 \pm 1$ & $(2.8 \pm 0.07) \times 10^{16}$ & $5.6 \times 10^{-9}$ & Cummins et al. (1986) \\
\hline & & & $26_{-12}^{+138}$ & $8.1_{-4}^{+8} \times 10^{15}$ & $1.6 \times 10^{-9}$ & Turner (1991) \\
\hline & & II & $120 \pm 20$ & $(3.5 \pm 0.5) \times 10^{15}$ & $7 \times 10^{-10}$ & Cummins et al. (1986) \\
\hline & & & $204_{-81}^{+392}$ & $6.9_{-3.1}^{+5.6} \times 10^{15}$ & $1.4 \times 10^{-9}$ & Turner (1991) \\
\hline & \multirow[t]{2}{*}{$\mathrm{C}_{2} \mathrm{H}_{5} \mathrm{OH}$} & & 14 & $5.3 \times 10^{14}$ & $1.1 \times 10^{-10}$ & Cummins et al. (1986) \\
\hline & & & 36 & $4.8_{-2.4}^{+4.5} \times 10^{15}$ & $9.6 \times 10^{-10}$ & Turner (1991) \\
\hline & \multirow[t]{2}{*}{$\mathrm{CH}_{3} \mathrm{OCH}_{3}$} & & 24 & $5 \times 10^{14}$ & $1 \times 10^{-10}$ & Cummins et al. (1986) \\
\hline & & & $80_{-37}^{+351}$ & $2.3_{-0.4}^{+0.9} \times 10^{15}$ & $4.6 \times 10^{-10}$ & Turner $(1991)^{e}$ \\
\hline \multicolumn{7}{|c|}{ W51e2 } \\
\hline & \multirow[t]{2}{*}{$\mathrm{CH}_{3} \mathrm{OH}$} & & 208 & $1.0 \times 10^{17}$ & $2.7 \times 10^{-7}$ & Ikeda et al. (2002) \\
\hline & & a-type & $101 \pm 4$ & $2.5_{-0.3}^{+0.5} \times 10^{16}$ & $6.9 \times 10^{-8}$ & this work \\
\hline & \multirow[t]{2}{*}{$\mathrm{C}_{2} \mathrm{H}_{5} \mathrm{OH}$} & & $169 \pm 28$ & $(3.1 \pm 1.1) \times 10^{15}$ & $8.6 \times 10^{-9}$ & Ikeda et al. (2002) \\
\hline & & & $143 \pm 20$ & $1.6_{-0.3}^{+0.4} \times 10^{15}$ & $4.4 \times 10^{-9}$ & this work \\
\hline & $\mathrm{CH}_{3} \mathrm{OCH}_{3}$ & & $145 \pm 8$ & $1.6_{-0.2}^{+0.4} \times 10^{16}$ & $4.4 \times 10^{-8}$ & this work \\
\hline & $\mathrm{C}_{2} \mathrm{H}_{5} \mathrm{OCH}_{3}$ & & $69 \pm 94$ & $2_{-1.9}^{+29} \times 10^{14}$ & $5.6 \times 10^{-10}$ & this work \\
\hline
\end{tabular}

${ }^{a}$ We used $N\left(\mathrm{H}_{2}\right)(\mathrm{G} 34.26)=4 \times 10^{23} \mathrm{~cm}^{-2}, N\left(\mathrm{H}_{2}\right)(\mathrm{NGC} 6334 \mathrm{I})=2 \times 10^{23} \mathrm{~cm}^{-2}, N\left(\mathrm{H}_{2}\right)($ Orion KL $)=1 \times 10^{23} \mathrm{~cm}^{-2}, N\left(\mathrm{H}_{2}\right)(\mathrm{SgrB} 2(\mathrm{~N}))=5 \times 10^{24} \mathrm{~cm}^{-2}$ and $N\left(\mathrm{H}_{2}\right)(\mathrm{W} 51 \mathrm{e} 2)=3.6 \times 10^{23} \mathrm{~cm}^{-2}$, see Sect. 4 .

${ }^{b}$ Observed at center of G34.26, as opposed to the halo.

${ }^{c}$ The Onsala and CIT survey (see Turner 1991) did not find any ethanol towards Orion KL and estimated an upper limit between 1.5 and $4 \times 10^{14} \mathrm{~cm}^{-2}$.

${ }^{d}$ Cummins et al. (1986) and Turner (1991) used two rotational temperature diagrams (I and II) to fit the observed $\mathrm{CH}_{3} \mathrm{OH}$ lines. Cummins et al. (1986) uses the transitions with $E_{u}$ below $70 \mathrm{~K}$ for the fit I whereas Turner (1991) splits the two components I and II at $E_{\mathrm{u}}=40 \mathrm{~K}$.

${ }^{e}$ Turner (1991) gives two fits of $T_{\text {rot }}$ and $N_{\mathrm{t}}$, the values used here correspond to the most reliable fit. 

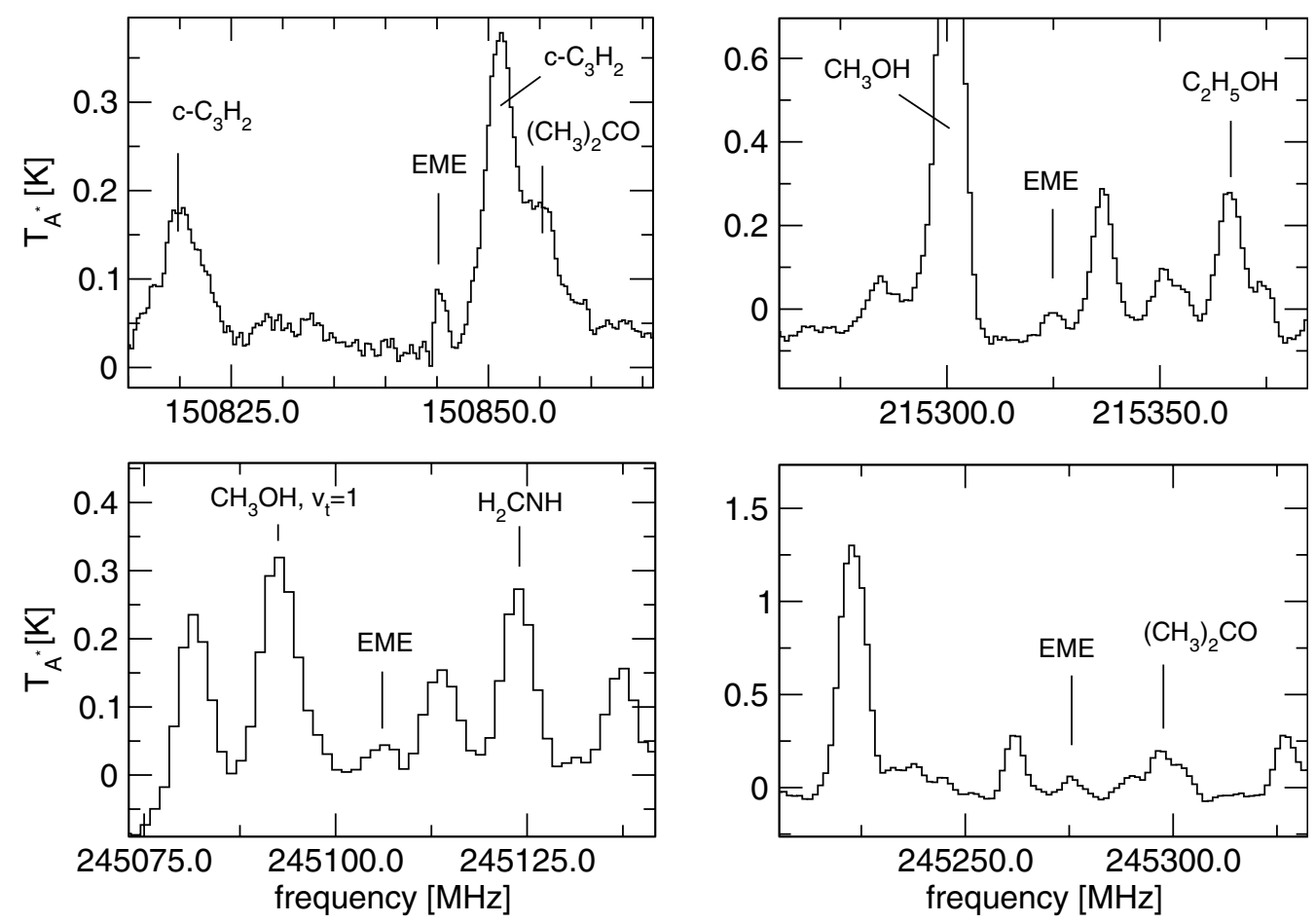

Fig. 3. Spectra recorded towards W51e2. The EME transitions $20_{0,20}-19_{1,19}$ at $150845.5 \mathrm{MHz}, 19_{5,14}-19_{4,15}$ at $215325.4 \mathrm{MHz}, 16_{3,14}-15_{2,13}$ at $245106.4 \mathrm{MHz}$, and $17_{3,15}-16_{2,14}$ at $245190.7 \mathrm{MHz}$ are indicated.

is characterized by a rotational thermal equilibrium temperature. For each source a simulated spectrum has been created which covered all measured frequency bands. This enables an estimate of the abundances and temperatures of the molecules in these sources and can help to reveal blendings of several lines at a given frequency position. myXCLASS is specially suited to deal with many convoluting line profiles with different line widths and intensities as can regularly be observed in hot core regions where lines of different molecules blend with each other.

The spatial extent of the molecule can influence the value of the inferred column density. This is because the circular Gaussian beam size diameter $\theta_{B}$ of the telescope varies with frequency $v$, i.e. $\theta_{B} \sim 1 / v$ (see telescope beam $H P B W$ in the online table). If the telescope beam points towards a source of circular Gaussian type with size $\theta_{S}$ the resulting convolution beam filling factor $b$ is given by $b=\theta_{S}^{2} /\left(\theta_{B}^{2}+\theta_{S}^{2}\right)$, see Snyder et al. (2005) and the work by Ulich \& Haas (1976). In the case of $\theta_{S} \gg \theta_{B}$ the beam filling factor is close to unity, for $\theta_{S} \sim \theta_{B}$ the beam dilution is 0.5 and for $\theta_{S} \ll \theta_{B}$ it follows $b \approx \theta_{S}^{2} / \theta_{B}^{2}$. Thus, assuming that the intrinsic intensity distribution $T_{\mathrm{S}}$ of a source is Gaussian, a beam filling factor can be introduced to calculate the measured intensity $T_{\mathrm{mb}}=b \cdot T_{\mathrm{S}}$. HMCs are compact objects with diameters $<10^{\prime \prime}$. Using the IRAM $30 \mathrm{~m}$ telescope with $H P B W$ around $30^{\prime \prime}$ and $10^{\prime \prime}$ at 80 and $250 \mathrm{GHz}$ respectively and assuming a $10^{\prime \prime}$ source size the beam filling factor is $b(@ 80 \mathrm{GHz})=0.1$ and $b(@ 250 \mathrm{GHz})=0.5$. Hence, an intensity difference of a factor 5 can occur by not correcting for beam dilution. The program myXCLASS has the source size as an input parameter and can thus simulate the effect of the assumed source size on the line intensities.
For the EME lines we can expect small optical depths so that the rotational temperature $T_{\text {rot }}$ and the total molecular column density $N_{\mathrm{T}}\left[\mathrm{cm}^{-2}\right]$ can be determined by a least-squares fit of

$$
\log _{10}\left(\frac{3 k_{B}}{8 \pi^{3}} \frac{\int T_{\mathrm{mb}} \mathrm{d} v}{v \mu^{2} S}\right)=\log _{10}\left(\frac{N_{\mathrm{T}}}{Q\left(T_{\mathrm{rot}}\right)}\right)-\frac{\log _{10}(e) E_{u}}{T_{\text {rot }}}
$$

with $\int T_{\mathrm{mb}} \mathrm{d} v$ the observed line integral, $\mu^{2} S$ the dipole and line strength value derived from Pickett et al. (1998) (see their Eq. (2)), $Q$ the partition function, and $E_{\mathrm{u}}$ the energy of the upper level. The resulting fit can be plotted in a rotationaltemperature-diagram (RTD) or Boltzmann plot. For detections at the confusion limit Snyder et al. (2005) has shown that Boltzmann plots cannot necessarily be used as independent tools to verify interstellar spectral line identifications. Any false assignment does not automatically reveal itself in the RTD by large displacements from the fitted line and thus can only be avoided by careful line check in catalogs and the literature. As a standard procedure any candidate line of EME has to be checked against competing lines, i.e. the expected or known intensities of these other lines at the EME frequencies have to be determined. Therfore, a consistent and comprehensive list of molecule abundances in the source is important. Line surveys are invaluable aids in determining the chemical composition of a source.

\section{Results}

\subsection{W51e2}

Several lines at EME transitions have been observed towards W51e2, see Fig. 3. We looked for strong EME $b$-type lines 


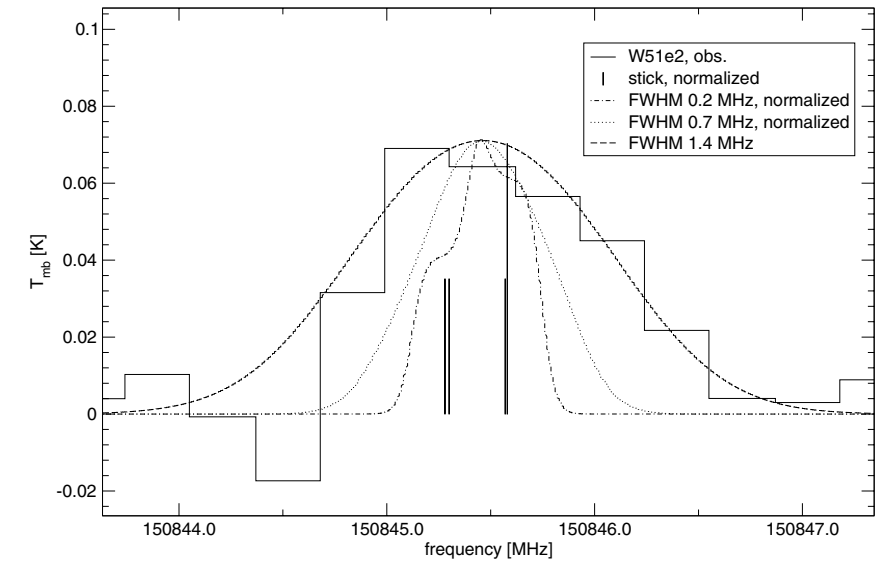

Fig. 4. The $20_{0,20}-19_{1,19}$ transition of EME at $150845.5 \mathrm{MHz}$. The line profile observed towards W51e2 (bold) is compared to three simulated line profiles (dashed) of $0.2,0.7$, and $1.4 \mathrm{MHz}$ line widths $(F W H M)$. For a line width of $0.2 \mathrm{MHz}(F W H M)$ the splitting due to internal torsional motion of the molecule is partly resolved. The stick diagram indicates the position and relative intensities of the split lines based on our recent high resolution laboratory measurements Fuchs et al. (2003). For comparison with the observed spectrum all simulated spectra are normalized to have the same peak intensity.

and at the same time tried to exclude as many blendings with other molecules. By using myXCLASS we first estimated a column density of $\sim 10^{14} \mathrm{~cm}^{-2}$ and a rotational temperature of roughly $100 \mathrm{~K}$. We checked every frequency band for consistency by comparing a simulated spectrum of EME and other known molecules with the observed spectrum. Figure 4 shows an observed line with simulated EME lines superimposed. The laboratory measurements of the EME line positions are at a precision level unmatched by any astronomical observations. The figure illustrates the effect of the linewidth on the total observable line shape and shows that the unique EME feature which is due to the torsional splitting remains unresolved in the observed spectrum. The observed lines ${ }^{5}$ at transition frequencies of EME are shown in Table 3. The more stronger lines can be found above $150 \mathrm{GHz}$ whereas many lines at the $1 \sigma-2 \sigma$ level have been observed at lower frequencies. Hot cores reveal a great richness and density in molecular emission lines, see Fig. 8, and it is not astonishing that $77 \%$ of the EME lines in the observed bands are blended by strong lines of other known molecules. In our case by far the most blendings occur in the $215 \mathrm{GHz}$ band which is therefore not further detailed in Table $3.12 \%$ of the blendings are at line positions of yet unidentified species. However, from intensity considerations it is clear that these latter lines cannot be dominated by EME because in this case EME should have also strong lines at other frequencies where we have not observed any strong feature. Note that many transition in Table 3 have labels with possible blendings. By carefully checking the databases and literature but also by fitting many other species to our spectra we could estimate the abundances of several species which could be potential competitors to the EME lines. To further clarify our detection we made two Boltzmann fits, as shown in Fig. 5. Here,

\footnotetext{
5 The $5_{3,2}-4_{2,3}$ transition line at $160.1 \mathrm{GHz}$ from Charnley et al. (2001) is not listed in Table 3 and has not been considered in our fits.
}

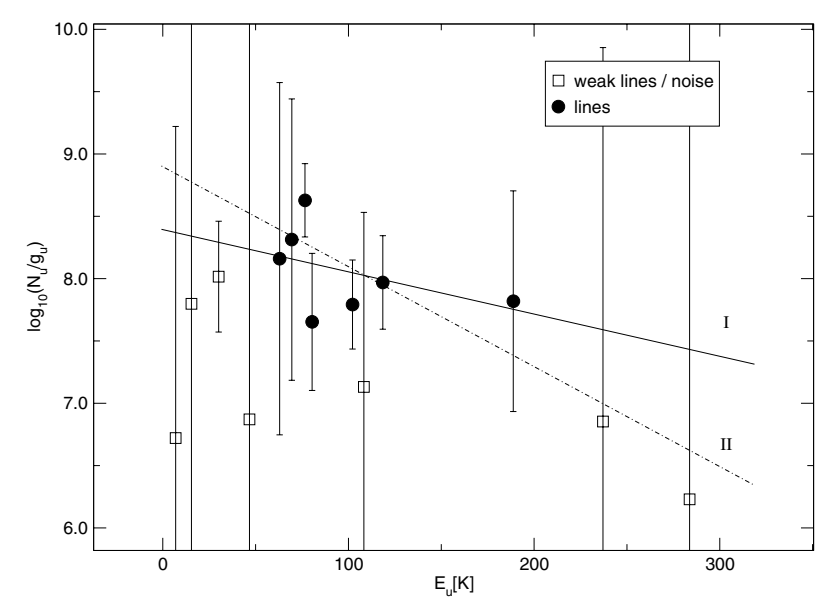

Fig. 5. Boltzmann plot for the EME transitions found towards W51e2 based on 14 observed lines, assuming no beam dilution. Due to difficulties in assigning the lines to EME two fits have been performed. I) Fit including all lines marked with $\square$ and • in Table 3. Here $T_{\text {rot }}=126 \pm 115 \mathrm{~K}$ and $\log \left(N_{\mathrm{t}}\right)=14.9 \pm 0.7$. II) Fit using only lines with intensities $\geq 2 \sigma(\bullet)$ resulting in $T_{\text {rot }}=54 \pm 38 \mathrm{~K}$ and $\log \left(N_{\mathrm{t}}\right)=14.3 \pm 1.2$. Lines which are less than $2 \sigma$ intense are marked with an $\square$.

every line in Table 3 which is marked with an $(\bullet)$ or $(\square)$ is depicted. If we use all these 14 lines in the Boltzmann fit (I) we get $T_{\text {rot }}=126 \pm 115 \mathrm{~K}$ and $N_{\mathrm{t}}=7.9_{-6}^{+32} \times 10^{14} \mathrm{~cm}^{-2}$ as the beam averaged column density. Since we have many weak lines (i.e. around $1 \sigma$ level) the reliability of the fit can be checked by excluding the weaker or doubtful lines marked with ( $\square=$ noisy-like). Fit (II) only includes lines $(\bullet)$ with intensities larger than $2 \sigma$. As a result we obtain $T_{\text {rot }}=54 \pm 38 \mathrm{~K}$ and $N_{\mathrm{t}}=6.3_{-5}^{+25} \times 10^{14} \mathrm{~cm}^{-2}$. This fit II should be regarded as more reliable than fit I. Furthermore, it has been shown that the excluded weak and noisy lines $(\square)$ are not in contradiction to fit II. Due to the large errors of the weak lines in the Boltzmann plot this is indeed not the case, but we would still expect slightly higher intensities at the $(\square)$ frequency positions.

W51e2 is known to have a size $<10^{\prime \prime}$ so that the effect of beam dilution should be considered. For each fit (I and II) the above mentioned temperatures and abundances of EME can be recalculated by assuming an $5^{\prime \prime}$ source size. This results in source averaged column densities and temperatures: fit I gives $T_{\text {rot }}=74 \pm 50 \mathrm{~K}$ and $N_{\mathrm{t}}=2_{-1.5}^{+8} \times 10^{14} \mathrm{~cm}^{-2}$, fit II $T_{\text {rot }}=69 \pm 94 \mathrm{~K}$ and $N_{\mathrm{t}}=2_{-1.9}^{+29} \times 10^{14} \mathrm{~cm}^{-2}$. Hence, the column densities and temperatures of the diluted and non-diluted beam yield comparable results within their error limits and we will use the source averaged value of fit (II) for further investigations. As has already been stated, RTDs cannot necessarily be used as reliable independent evidence to support the detection of a molecule close to the confusion limit, as was shown by Snyder et al. (2005) in the case of glycine. Our estimated column density is also consistent with observations in less favored frequency regions as can be seen in Fig. 6 where an EME line is expected. For our fitted $2 \times 10^{14} \mathrm{~cm}^{-2}$ column density no contradiction within the $1 \sigma$ level can be found, but for a $N_{\mathrm{t}}=4-8 \times 10^{14} \mathrm{~cm}^{-2}$ the simulated spectrum is in clear conflict with observation. 
Table 3. EME transitions observed in W51e2.

\begin{tabular}{|c|c|c|c|c|c|c|c|c|}
\hline Transition & $\begin{array}{c}\text { Observed } \\
\text { frequency }^{a} \\
(\mathrm{MHz})\end{array}$ & $\begin{array}{c}\text { Theor. } \\
\text { frequency } \\
(\mathrm{MHz})\end{array}$ & $\begin{array}{c}\text { Obs-calc } \\
(\mathrm{MHz})\end{array}$ & $\begin{array}{c}\text { line } \\
\text { components }\end{array}$ & $\begin{array}{c}E_{\text {upper }} \\
(\mathrm{K})\end{array}$ & $\begin{array}{c}\int T_{\mathrm{mb}} \mathrm{d} v \\
\left(\mathrm{~K} \mathrm{~km} \mathrm{~s}^{-1}\right)\end{array}$ & & \\
\hline $11_{2,10}-11_{1,11}$ & $80882.3(5)^{b}$ & $80882.7(10)^{d}$ & -0.4 & 5 & 30.1 & $0.09(4)$ & $\square$ & $\mathrm{n}$ \\
\hline $24_{1,23}-24_{0,24}$ & 81 198.4(1) & 81 198.7(5) & -0.3 & 5 & 118.5 & $0.16(6)$ & $\bullet$ & $\mathrm{c}_{1}$ \\
\hline $35_{3,32}-35_{2,33}$ & $91439.6(5)$ & $91440.4(10)$ & -0.8 & 5 & 255.2 & $1.0(44)$ & & $\mathrm{b}$ \\
\hline $36_{3,33}-36_{2,34}$ & - & $91475.6(9)$ & & 5 & 269.3 & & & $\mathrm{~b}$ \\
\hline $34_{2,32}-34_{1,33}$ & $91630.1^{e}$ & $91630.8(5)$ & -0.7 & 5 & 237.1 & $0.03(9)$ & $\square$ & $\mathrm{c}_{2}, \mathrm{n}$ \\
\hline $34_{3,31}-34_{2,32}$ & - & $91688.3(10)$ & - & 5 & 241.5 & - & & $\mathrm{n}$ \\
\hline $37_{3,34}-37_{2,35}$ & $91812.7(4)$ & $91812.6(9)$ & 0.1 & 5 & 283.7 & $0.1(5)$ & $\square$ & $\mathrm{n}$ \\
\hline $35_{2,33}-35_{1,34}$ & - & $96207.0(9)$ & - & 5 & 250.8 & - & & $\mathrm{b}$ \\
\hline $29_{3,26}-29_{2,27}$ & $96390.8(3)$ & $96391.4(12)$ & -0.6 & 5 & 179.1 & $1.85(37)$ & & $\mathrm{b}$ \\
\hline $3_{2,1}-2_{1,2}$ & $96464.1^{e}$ & $96464.3(6)$ & -0.2 & 5 & 6.9 & $0.002(5)$ & $\square$ & $\mathrm{n}$ \\
\hline $22_{3,19}-22_{2,20}$ & $107654.8^{e}$ & $107656.8(14)$ & -2.0 & 5 & 108.3 & $0.05(7)$ & $\square$ & $\mathrm{n}$ \\
\hline $7_{2,5}-6_{1,6}$ & $131350.2(10)$ & $131350.7(8)$ & -0.5 & 5 & 15.4 & $0.02(6)$ & $\square$ & $\mathrm{c}_{3}, \mathrm{n}$ \\
\hline $15_{1,15}-14_{0,14}$ & $131372.68(80)$ & $131372.8(5)$ & -0.12 & 5 & 46.7 & $0.02(10)$ & $\square$ & $\mathrm{c}_{4}, \mathrm{n}$ \\
\hline $36_{1,35}-36_{0,36}$ & - & $150502.4(19)$ & & 5 & 260.06 & - & & $\mathrm{b}$ \\
\hline $34_{4,30}-34_{3,31}$ & $150661.3(6)$ & $150662.9(16)$ & -1.6 & 5 & 248.7 & $0.12(2)$ & & $\mathrm{b}$ \\
\hline $13_{6, x}-14_{5, y}$ & $150794.1^{e}$ & $150794.1(18)$ & 0.0 & 10 & 76.6 & $0.17(0.05)$ & $\bullet$ & $\mathrm{c}_{5}$ \\
\hline $20_{0,20}-19_{1,19}$ & $150845.52(30)$ & $150845.5(2)$ & 0.02 & 5 & 80.4 & $0.20(11)$ & $\bullet$ & $\mathrm{c}_{6}$ \\
\hline $\begin{array}{c}{[\ldots]^{f}} \\
19_{5, x}-19_{4,15} \\
{[\ldots]^{f}}\end{array}$ & $215325.4^{e}$ & $215326.3(13)$ & -0.9 & 6 & 102.2 & $0.28(10)$ & $\bullet$ & $\begin{array}{l}\mathrm{b} \\
\mathrm{b}\end{array}$ \\
\hline $28_{0,28}-27_{1,27}$ & $217939.6(3)$ & $217940.7(1)$ & -1.1 & 5 & 154.7 & $3.66(19)$ & & $\mathrm{b}$ \\
\hline $16_{3,14}-15_{2,13}$ & $245106.4(32)$ & $245104.7(29)$ & 1.43 & 5 & 62.9 & $0.46(65)$ & $\bullet$ & $\mathrm{c}_{7}$ \\
\hline $31_{1,31}-30_{0,30}$ & $245275.0(13)$ & $245274.1(1)$ & 0.86 & 5 & 188.8 & $0.87(77)$ & $\bullet$ & \\
\hline $17_{3,15}-16_{2,14}$ & $252190.7(11)$ & 252 189.4(29) & 1.3 & 5 & 69.5 & $0.70(79)$ & $\bullet$ & $\mathrm{c}_{8}$ \\
\hline $28_{2,27}-27_{1,26}$ & $253309.3(3)$ & $253308.2(12)$ & 1.09 & 5 & 161.0 & $16.01(126)$ & & $\mathrm{b}$ \\
\hline
\end{tabular}

a Rest frequencies (assuming a source LSR velocity of $+55 \mathrm{~km} \mathrm{~s}^{-1}$ ) in W51e2.

$b$ The numbers in parenthesis are the estimated uncertainties $(1 \sigma)$.

$c$ Frequencies are taken from Fuchs et al. (2003).

$d$ The deviation from the mean frequency of the transitions to its extreme values, e.g. due to rotational and internal rotational splitting the transition $11_{2,10}-11_{1,11}$ is split in 5 transitions which occur between $80881.7-80883.6 \mathrm{GHz}$, thus the frequency denoted in the table is $80882.7(10)$.

$e$ Manually determined (or in case of noise the closest peak). Here the transition $13_{6, x}-15_{5, y}$ are with $x-y=7-9,7-10,8-9,8-10$ and the $x$ in $19_{5, x}-19_{4,15}$ denotes either 14 or 15 .

$f$ Region with many blends of EME with other (dominating) molecules.

- Lines included in the Boltzmann fit II, see Fig. 5.

$\square$ Lines included in the Boltzmann fit I and II, see Fig. 5.

n "Noisy" line, i.e. a line which has either less than $2 \sigma$ intensity or where the intensity is difficult to obtain due to baseline variations.

b Denotes a blend with an other molecular line where the other line contributes most to the total intensity.

$\mathrm{c}_{i}$ Denotes a contribution of another molecule to the total intensity where the blended line is estimated to contribute less than $20 \%$ (if not otherwise mentioned) compared to EME. Assuming $T_{\text {rot }} \sim 100 \mathrm{~K}$ :

$\mathrm{c}_{1} \mathrm{C}_{2} \mathrm{H}_{5} \mathrm{OOCH}$ with $N \leq 5 \times 10^{15} \mathrm{~cm}^{-2}$ (could be up to 50\%), $\mathrm{c}_{2} \mathrm{HOONO}_{2}$ with $N \leq 5 \times 10^{14} \mathrm{~cm}^{-2}, \mathrm{c}_{3} \mathrm{c}_{-} \mathrm{H}_{2} \mathrm{C}_{3} \mathrm{O}$ with $N \leq 2 \times 10^{12} \mathrm{~cm}^{-2}$, $\mathrm{c}_{4} \mathrm{C}_{2} \mathrm{H}_{3} \mathrm{NH}_{2}$ with $N \leq 8 \times 10^{15} \mathrm{~cm}^{-2}, \mathrm{c}_{5} \mathrm{C}_{3} \mathrm{H}_{7} \mathrm{CN}$ with $N \leq 2 \times 10^{14} \mathrm{~cm}^{-2}, \mathrm{c}_{6} \mathrm{C}_{2} \mathrm{H}_{5} \mathrm{C}^{15} \mathrm{~N}$ with $N \leq 3 \times 10^{13} \mathrm{~cm}^{-2}$ based on our observation that $\mathrm{C}_{2} \mathrm{H}_{5} \mathrm{CN}$ has $N \sim 3 \times 10^{14} \mathrm{~cm}^{-2}, \mathrm{c}_{7} \mathrm{CH}_{2}(\mathrm{OH}) \mathrm{CHO}$ with $N \leq 8 \times 10^{14} \mathrm{~cm}^{-2}, \mathrm{c}_{8}$ a- $\mathrm{H}_{2} \mathrm{C}=\mathrm{CHOH}$ with $N \leq 2 \times 10^{14} \mathrm{~cm}^{-2}$. 


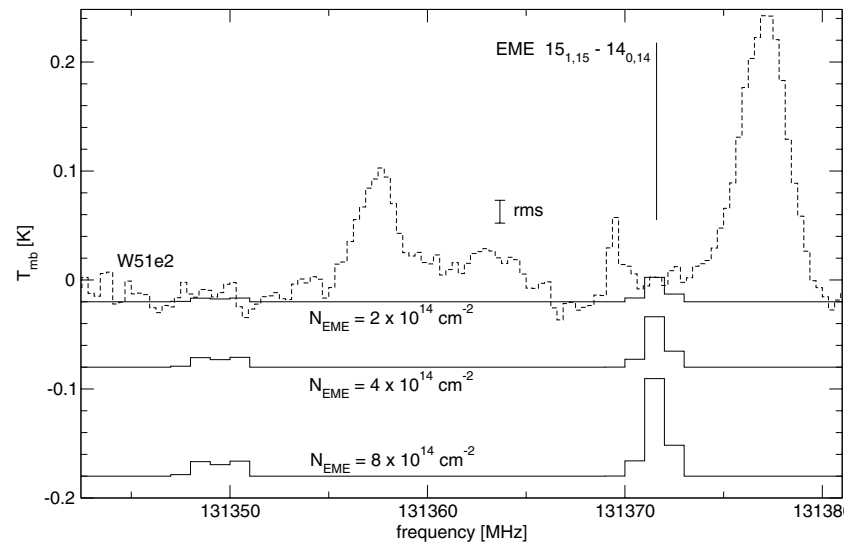

Fig. 6. Observed spectrum at W51e2 (top, dashed) and calculated spectra for different column densities of EME at $70 \mathrm{~K}$.

It is commonly believed that most complex molecules exist within a small area around the forming star, e.g. around $5^{\prime \prime}$ for W51e2. On the other hand Hollis et al. (2001) have shown that complex molecules such as glycolaldehyde can be found on spatial scales of $\geq 60^{\prime \prime}$ in the case of SgrB2. With our data it is not possible to determine the size of the emitting region but the source size has surely an influence on the detected signal strength which we tried to estimate using the myXCLASS program. Table 4 lists the result of possible column densities consistent with the observations if we assume certain temperatures between $30 \mathrm{~K}$ and $150 \mathrm{~K}$. Charnley et al. (2001) presented a map of a line at an EME transition frequency towards SgrB2 of the order of $20^{\prime \prime}$. If we assume W51e2 to have this same source size the column density would have to be corrected to lower values by nearly an order of magnitude. More realistic, our best fit value (fit II) assumes an 5" size of W51e2.

Furthermore, it can be seen from Fig. 7 (see simulated spectrum for $N=1 \times 10^{15} \mathrm{~cm}^{-2}$ ) that in some frequency regions strong EME lines, i.e. lines well above $3 \sigma$ level, should reveal their internal line splitting. Due to the weakness of the observed lines no line was detected where the torsional splitting could be resolved so that there is no unique proof that these lines indeed belong to EME.

\subsection{The other sources}

Sample spectra showing all examined sources at $245 \mathrm{GHz}$ are shown in Fig. 8. At this frequency one of the strongest observed EME candidate lines appears in W51e2. However, no line above $1 \sigma$ appears in these spectra for any other examined source. Also for the other frequency bands we get similar results. For example, the well pronounced feature at $150845 \mathrm{MHz}$ in W51e2 is only at the $1-2 \sigma$ level in Orion KL and is completely invisible in G34.26 and NGC 6334I. An upper limit for the column density of G34.26, NGC 6334I and Orion KL has been estimated by the use of myXCLASS and independently by RTDs using integrated noise at EME transition frequencies and assuming an appropriate line width. Figure 7 compares the $215 \mathrm{GHz}$ region of W51e2 with Orion KL and also shows simulated spectra of EME for $N=2 \times 10^{14} \mathrm{~cm}^{-2}$ and $N=1 \times 10^{15} \mathrm{~cm}^{-2}$ at $70 \mathrm{~K}$ (assuming an $5^{\prime \prime}$ source size). It
Table 4. Estimated column density for various source sizes and rotational temperatures for W51e2.

\begin{tabular}{cl|l}
\hline \hline $\begin{array}{c}\text { source size } \\
\text { [arcsec }]\end{array}$ & $\begin{array}{l}T_{\text {rot }} \\
{[\mathrm{K}]}\end{array}$ & $\begin{array}{c}\text { column density } \\
{\left[\mathrm{cm}^{-2}\right]}\end{array}$ \\
\hline $20^{\prime \prime}$ & 30 & $\sim 5 \times 10^{13}$ \\
& 50 & $\sim 4 \times 10^{13}$ \\
& 70 & $\sim 4 \times 10^{13}$ \\
$10^{\prime \prime}$ & 50 & $\sim 8 \times 10^{13}$ \\
& 70 & $\sim 9 \times 10^{13}$ \\
& 150 & $1.3 \times 10^{14}$ \\
$5^{\prime \prime}$ & 70 & $2.0 \times 10^{14}$ \\
& 150 & $4.5 \times 10^{14}$ \\
\hline
\end{tabular}

is immediately clear that the column densities of these sources must be of the order of $10^{14} \mathrm{~cm}^{-2}$ or less rather than $10^{15} \mathrm{~cm}^{-2}$ as estimated by Charnley et al. (2001).

Our results are summarized in Table 2. The previously published line at the EME $5_{3,2}-4_{2,3}$ transition frequency at 160.1 GHz in Orion KL by Charnley et al. (2001) has not been considered in the fit.

\section{Discussion}

Charnley et al. (2001) estimate the column density of EME in Orion KL and SgrB2(N) to be between $10^{14}-10^{15} \mathrm{~cm}^{-2}$ and in W51 to be a few times $10^{14} \mathrm{~cm}^{-2}$. EME column densities at around $10^{14} \mathrm{~cm}^{-2}$ correspond to signal strengths which are already close to the confusion limit in the HMC spectra. Nevertheless, long integration times and the availability of spectra at many frequencies enable us to estimate the column density of Orion KL to be below $1 \times 10^{14} \mathrm{~cm}^{-2}$ and those of G34.26 and NGC 6334I to be of the same order.

We can now use our values in Table 2 of W51e 2 to draw some conclusions using the model of Charnley et al. (1995). According to Figs. 2 and $3 \mathrm{a}$ in their paper, which assumes a $10^{-6}$ fractional abundance $X_{\text {Eol }}$ of ethanol as a starting value for the chemical evolution in their model, the age of W51e2 should be either $\geq 10^{5} \mathrm{yr}$ if we use $\mathrm{CH}_{3} \mathrm{OH}$ or $\mathrm{C}_{2} \mathrm{H}_{5} \mathrm{OH}$ as a probe molecule or $10^{4}-10^{5}$ if we look at $\mathrm{CH}_{3} \mathrm{OCH}_{3}$. However, that would imply a fractional abundance between $\leq 10^{-10}$ and $\sim 3 \times 10^{-9}$ for EME. On the other hand, if we use Fig. 4a of Charnley et al. (1995) with ethanol starting at $X_{\mathrm{Eol}}=10^{-7}$ this translates to $X_{\mathrm{EME}} \leq 10^{-12}$ and $X_{\mathrm{EME}} \sim 4 \times 10^{-10}$. Assuming $\mathrm{C}_{2} \mathrm{H}_{5} \mathrm{OH}$ to be the best molecule to determine the chemical age of the HMC it appears that in both cases, i.e. with ethanol starting values or $X_{\mathrm{Eol}}=10^{-6}$ and $X_{\mathrm{Eol}}=10^{-7}$, the fractional abundance of EME is nearly the same, namely $X_{\mathrm{EME}} \sim 2 \times 10^{-10}$. This value is close to our estimated abundance $5.6 \times 10^{-10}$ for EME in W51e2. According to Table 2 and the model by Charnley et al. (1995) Orion KL and NGC 6334F should be roughly of the same age as W51e2. Although we have only upper limits on the EME abundance in these sources it is clear that as a consequence the $\mathrm{C}_{2} \mathrm{H}_{5} \mathrm{OH}$ fractional abundance at $0 \mathrm{yr}$ must be $10^{-7}$ rather than $10^{-6}$. G34.26 is slightly older and SgrB2 is the oldest of the here discussed sources and should have an EME abundance $X_{\mathrm{EME}}$ of less than $10^{-10}$ (corresponding to less than $10^{14} \mathrm{~cm}^{-2}$ column density as we see it for Orion KL, G34.26 and NGC 6334I). This however is in 


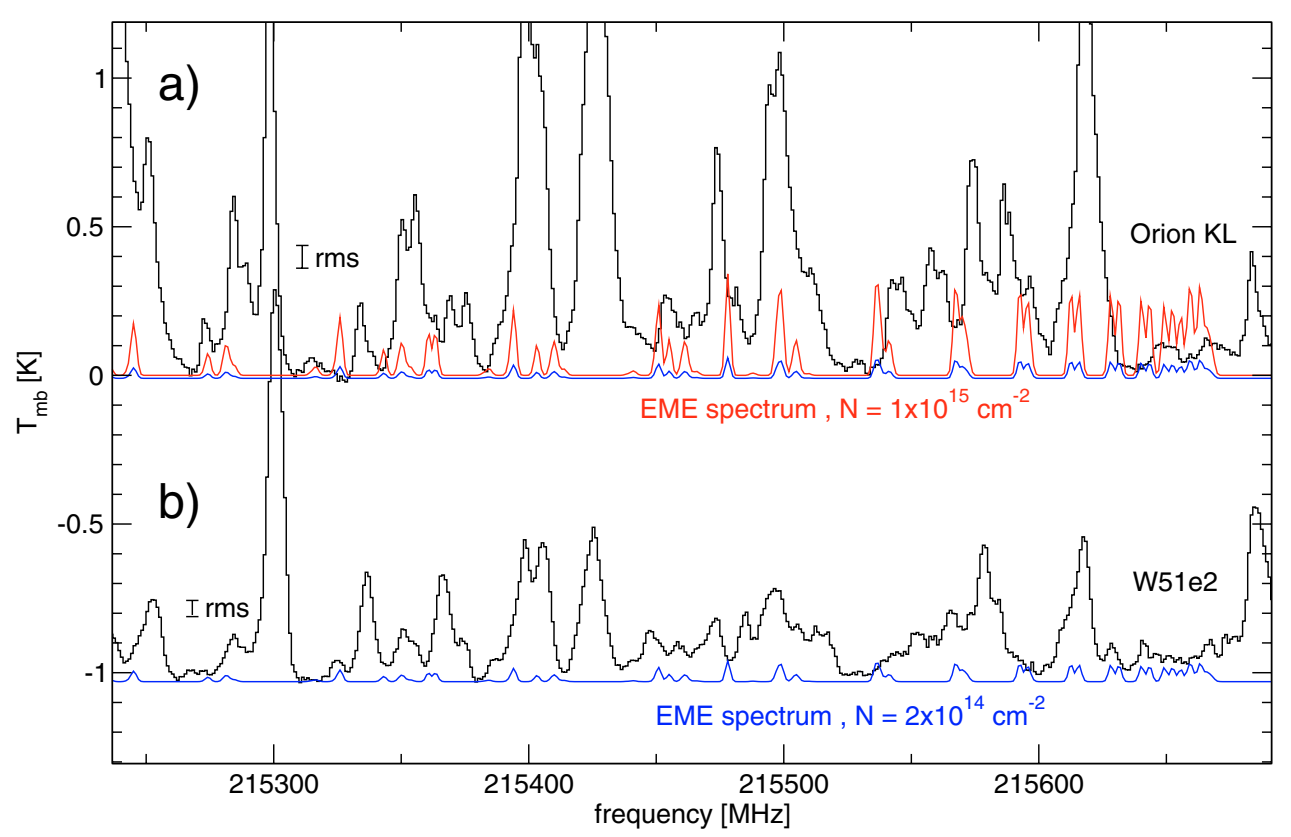

Fig. 7. Observed spectra of Orion KL and W51e 2 at $215 \mathrm{GHz}$. This frequency region has the highest line density of all our observed bands but even here gaps can be found where the presence of EME can be checked. Two simulated spectra of EME are plotted, i.e. $N=2 \times 10^{14} \mathrm{~cm}^{-2}$ (blue) and $N=1 \times 10^{15} \mathrm{~cm}^{-2}$ (red) with $T_{\text {rot }}=70 \mathrm{~K}$. The splitting of the lines which can best be seen above $215600 \mathrm{MHz}$ is mainly due to the internal rotation of the methyl groups of EME with an additional small asymmetry contribution. a) For Orion KL the previously estimated limits of $10^{14}-10^{15} \mathrm{~cm}^{-2}$ by Charnley et al. (2001) seem questionable as can be seen from the superimposed simulated spectra on the observed spectra. b) In the case of W51e2 the simulated spectrum is in agreement with the observation.

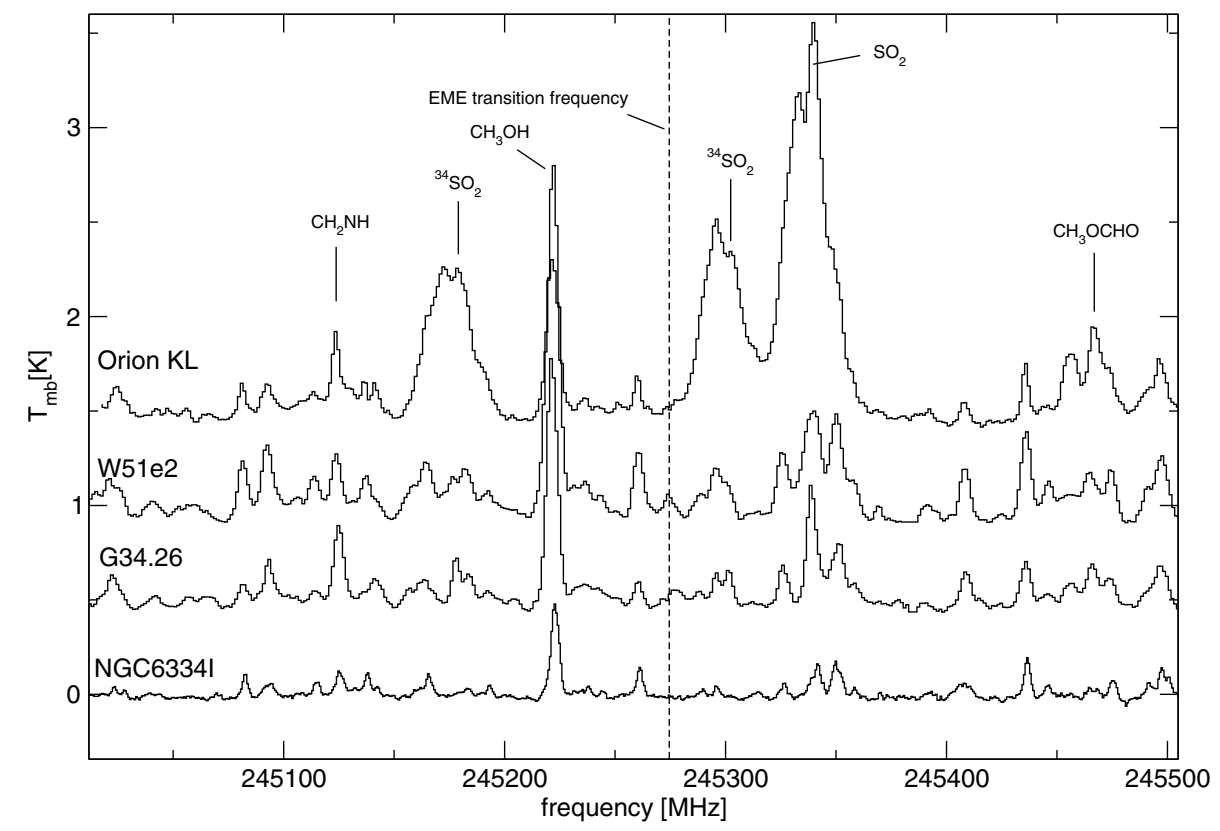

Fig. 8. Spectra of the observed sources at $245 \mathrm{GHz}$. Only W51e2 reveals a line at an EME transition frequency, whereas all other sources do not show any significant feature above $1 \sigma$ level. However, W51e2, G34.26 and NGC 6334I have similar spectra indicating the same chemical composition and equivalent dynamics.

contradiction to the claimed observations of EME towards SgrB2 by Charnley et al. (2001) when they estimate an abundance of $10^{-10}-10^{-9}$.

Looking at the observed values only, we notice that Orion $\mathrm{KL}$ has the highest fractional abundance of ethanol relative to $\mathrm{H}_{2}$ followed by NGC6334I, G34.26, W51e2 and then SgrB2(N). However, no EME has been detected in Orion KL.
The relative abundances of DME with respect to methanol and ethanol are shown in Fig. 9. Here, W51e2 shows a high dimethyl ether content relative to methanol and ethanol compared to the other sources, which may be a general indication of a higher ether abundance relative to the alcohols. Assuming that we indeed have detected EME in W51e2 the ratio between EME and ethanol is 0.13 which is 5 times less than 


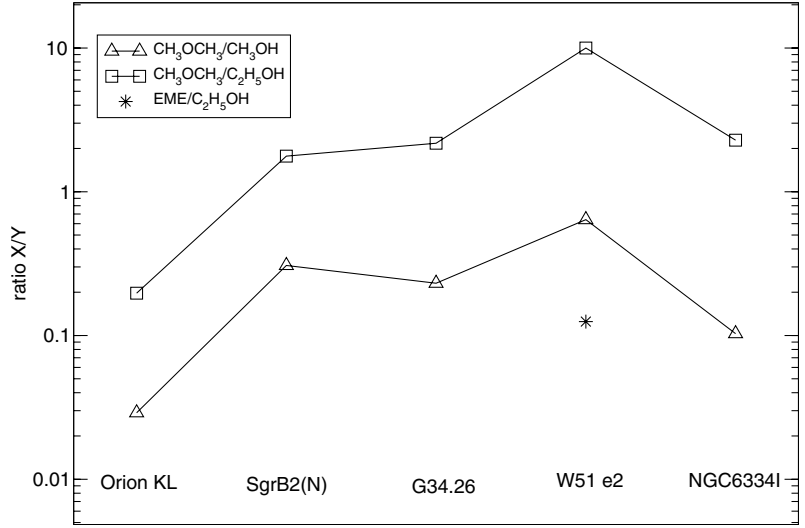

Fig. 9. Relative abundances of $\mathrm{CH}_{3} \mathrm{OH}, \mathrm{C}_{2} \mathrm{H}_{5} \mathrm{OH}, \mathrm{CH}_{3} \mathrm{OCH}_{3}$ derived from Table 2 by using the values from Turner (1991) for Orion KL, Turner (1991) for SgrB2(N), Thompson et al. (1999) and Ikeda et al. (2002) for G34.26, this work for W51e2 and Nummelin et al. (1998b) for NGC 6334I. The ratio of EME/ $\mathrm{C}_{2} \mathrm{H}_{5} \mathrm{OH}$ in W51e2 is 0.13 which is 5 times smaller than the ratio of $\mathrm{CH}_{3} \mathrm{OCH}_{3} / \mathrm{CH}_{3} \mathrm{OH}$.

the ratio of DME and methanol. If all sources would have a $0.13 \mathrm{EME} / \mathrm{ethanol}$ ratio the theoretical column densities would be around $2 \times 10^{14} \mathrm{~cm}^{-2}$ or higher ${ }^{6}$ which at least for G34.26, NGC 6334I and Orion KL has been shown to be not the case. Thus, W51e2 is indeed particularly rich in EME.

We conclude that only the tentative detection of EME by Charnley et al. (2001) towards W51e2 can be confirmed within the following caveats 1) the EME Boltzmann fits include a few lines close to the noise level, 2) the obtained temperature of $70 \mathrm{~K}$ for EME is lower than that of other observed molecules ( $2140 \mathrm{~K}$ ), 3) no torsional splitting of the EME lines could be observed and also other characteristic spectral fingerprints have not been observed. However, there are lines at EME transition frequencies which until now can best be explained by the existence of EME in W51e2.

Acknowledgements. We are grateful to the IRAM $30 \mathrm{~m}$ and SEST $15 \mathrm{~m}$ staff for their hospitality and assistance. Many thanks to Peter Schilke (MPIfR) for providing us with the myXCLASS program code. Many thanks to Eric Herbst for his invaluable suggestions and discussions. This work was supported by the Deutsche Forschungsgemeinschaft, DFG within SFB 494, IRAM, and ESO.

\section{References}

Blake, G., Sutton, E., Masson, C., \& Phillips, T. 1987, ApJ, 315, 621 Blake, G. A., Sutton, E., Masson, C., \& Phillips, T. 1986, ApJS, 60, 357

Bohme, D. K., Mackay, G. I., \& Tanner, S. 1979, Am. Chem. Soc., 101, 3724

Carpenter, J. H., \& Sanders, D. 1998, AJ, 116, 1856

Caselli, P., Hasegawa, T., \& Herbst, E. 1993, ApJ, 408, 548

Charnley, S. B., Kress, M., Tielens, A., \& Millar, T. 1995, ApJ, 448, 232

Charnley, S. B., Ehrenfreund, P., \& Kuan, Y.-J. 2001, Spectrochim. Acta. Part A, 57, 685

Cheung, L., Frogel, J., Gezari, D., \& Hauser, M. 1978, ApJ, 226, L149

Cummins, S. E., Linke, R., \& Thaddeus, P. 1986, ApJS, 60, 819
Durig, J., Jin, Y., Phan, H., Liu, J., \& Durig, D. 2002, Struct. Chem., 13,1

Friedel, D. N., Snyder, L. E., Turner, B. E., \& Remijan, A. 2004, ApJ, 600, 234

Fuchs, U. 2003, High Resolution Spectroscopy of Ethyl Methyl Ether and Hydrogen Cyanide Isotopomers (Göttingen: Cuvillier Verlag)

Fuchs, U., Winnewisser, G., Groner, P., De Lucia, F. C., \& Herbst, E. 2003, ApJS, 144, 277

Hayashi, M., \& Kuwada, K. 1975, J. Molec. Struct., 28, 147

Heaton, B. D., Little, L. T., \& Bishop, I. S. 1989, A\&A, 213, 148

Herbst, E. 2001, Chem. Soc. Rev., 30, 168

Hollis, J. M., Vogel, S. N., Snyder, L. E., Jewell, P. R., \& Lovas, F. J. 2001, ApJ, 554, L81

Hüttemeister, S., Wilson, T., Henkel, C., \& Mauersberger, R. 1993, A\&A, 276, 445

Ikeda, M., Ohishi, M., Nummelin, A., et al. 2001, ApJ, 560, 792

Ikeda, M., Ohishi, M., Nummelin, A., et al. 2002, ApJ, 571, 560

Johansson, L., Andersson, C., Elldér, J., et al. 1984, A\&A, 130, 227

Karpas, Z., \& Meot-Ner (Mautner), M. 1989, J. Phys. Chem., 93, 1859

Kuan, Y.-J., Charnley, S. B., Huang, H.-C., et al. 2004, Adv. Space. Res., 33, 31

Lee, C. W., \& Cho, S.-H. 2002, J. Korean. Astron. Soc., 35, 187

Liu, S.-Y., Mehringer, D. M., \& Snyder, L. E. 2001, ApJ, 552, 654

MacDonald, G. H., Gibb, A. G., Habing, R. J., \& Millar, T. J. 1996, A\&AS, 119, 333

Mackay, G., Tanner, S., Hopkinson, A., \& Bohme, D. 1979, Can. J. Chem., 57, 1518

Martín-Pintado, J., de Vicente, P., Wilson, T. L., \& Johnston, K. J. 1990, A\&A, 236, 193

McCutcheon, W., Sandell, G., Matthews, H., et al. 2000, MNRAS, 316,152

Millar, T. \& Hatchell, J. 1998, Chemistry and Physics of Molecules and Grains in Space, Faraday Discussions, 109, 15

Millar, T., Macdonald, G., \& Habing, R. 1995, MNRAS, 273, 25

Nomura, H., \& Millar, T. 2004, A\&A, 414, 409

Nummelin, A., Bergman, P., Friberg, P., et al. 1998a, ApJS, 117, 427

Nummelin, A., Dickens, J., Bergman, P., et al. 1998b, A\&A, 337, 275

Pickett, H., Poynter, R., Cohen, E., et al. 1998, J. Quant. Spectrosc. Radiat. Transfer, 60, 883

Remijan, A., Snyder, L., Liu, S.-Y., Mehringer, D., \& Kuan, Y.-J. 2002, ApJ, 576, 264

Remijan, A., Sutton, E., Snyder, L., et al. 2004, ApJ, 606, 917

Sandell, G. 2000, A\&A, 358, 242

Schilke, P., Groesbeck, T., Blake, G., \& Phillips, T. 1997, ApJS, 108, 301

Schloerb, F., Snell, R., \& Schwartz, P. 1987, ApJ, 319, 426

Snyder, L., Lovas, F., Hollis, J., et al. 2005, ApJ, 619, 914

Sutton, E., Blake, G. A., Masson, C., \& Phillips, T. 1985, ApJS, 58, 341

Sutton, E., Jaminet, P., Danchi, W., \& Blake, G. A. 1991, ApJS, 77, 255

Sutton, E., Peng, R., Danchi, W., et al. 1995, ApJS, 97, 455

Thompson, M., G. H. Macdonald, G., \& Millar, T. 1999, A\&A, 342, 809

Turner, B. 1989, ApJS, 70, 539

Turner, B. E. 1991, ApJS, 76, 617

Ulich, B., \& Haas, R. 1976, ApJS, 30, 247

Zhang, Q., Ho, P. T. P., \& Ohashi, N. 1998, ApJ, 494, 636

\footnotetext{
${ }^{6}$ Except for the SgrB2(N) value by Cummins et al. (1986).
} 
G. W. Fuchs et al.: Trans-ethyl methyl ether in space, Online Material p 1

\section{Online Material}


G. W. Fuchs et al.: Trans-ethyl methyl ether in space, Online Material p 2

Table 5. Observational parameters.

\begin{tabular}{|c|c|c|c|c|c|c|c|c|}
\hline $\begin{array}{l}\text { Receiver } \\
\text { frequency } \\
(\mathrm{MHz})\end{array}$ & $\begin{array}{l}T_{\text {sys }}^{a} \\
(\mathrm{~K})\end{array}$ & $\tau$ & $\begin{array}{l}\text { Tot. integr. } \\
\text { time (on + off) } \\
\quad(\min )\end{array}$ & $\rho^{b}$ & $\begin{array}{c}\text { Telescope } \\
\text { beam } H P B W \\
\left({ }^{\prime \prime}\right)\end{array}$ & $\begin{array}{c}1 \sigma(\mathrm{rms}) \\
\text { noise level } \\
\left(\mathrm{K} \text { as } T_{\mathrm{A}}^{*}\right)\end{array}$ & $\begin{array}{l}\text { Band } \\
\text { width } \\
(\mathrm{MHz})\end{array}$ & $\begin{array}{c}\text { Frequency } \\
\text { resolution } \\
(\mathrm{MHz})\end{array}$ \\
\hline \multicolumn{9}{|l|}{ G34.26 } \\
\hline 81041 & 144 & 0.03 & 85 & 0.79 & 30 & 0.012 & 490 & 0.3125 \\
\hline 91626 & 122 & 0.03 & 115 & 0.77 & 26 & 0.010 & 490 & 0.3125 \\
\hline 96371 & 137 & 0.02 & 145 & 0.77 & 25 & 0.014 & 490 & 0.3125 \\
\hline 131372 & 200 & 0.06 & 115 & 0.71 & 18 & 0.018 & 490 & 0.3125 \\
\hline 150750 & 307 & 0.04 & 220 & 0.68 & 16 & 0.017 & 490 & 0.3125 \\
\hline 215500 & 388 & 0.22 & 196 & 0.56 & 11 & 0.032 & 1020 & 1.0 \\
\hline 217900 & 350 & 0.14 & 147 & 0.55 & 11 & 0.023 & 1020 & 1.0 \\
\hline 245260 & 511 & 1.90 & 160 & 0.50 & 10 & 0.034 & 510 & 1.25 \\
\hline 252227 & 848 & 0.37 & 85 & 0.48 & 10 & 0.059 & 510 & 1.25 \\
\hline \multicolumn{9}{|l|}{ NGC 6334 I } \\
\hline 81198 & 327 & 0.41 & 38 & 0.76 & 59 & 0.009 & 994 & 0.6911 \\
\hline 91450 & 195 & 0.26 & 37 & 0.74 & 55 & 0.007 & 994 & 0.6911 \\
\hline 91630.7 & 185 & - & 87 & 0.74 & 55 & 0.005 & 994 & 0.6911 \\
\hline 91811.7 & 212 & 0.06 & 57 & 0.74 & 55 & 0.007 & 994 & 0.6911 \\
\hline 96380 & 252 & 0.21 & 55 & 0.73 & 53 & 0.009 & 994 & 0.6914 \\
\hline 150662 & 263 & 0.34 & 95 & 0.65 & 33 & 0.012 & 994 & 0.6989 \\
\hline 245105 & 513 & 0.96 & 77 & 0.47 & 22 & 0.024 & 994 & 0.6989 \\
\hline 245274 & 534 & 0.50 & 127 & 0.47 & 22 & 0.017 & 994 & 0.6989 \\
\hline \multicolumn{9}{|l|}{ Orion KL } \\
\hline 81041 & 138 & 0.03 & 125 & 0.79 & 30 & 0.012 & 490 & 0.3125 \\
\hline 91626 & 182 & 0.07 & 95 & 0.77 & 26 & 0.014 & 490 & 0.3125 \\
\hline 150750 & 316 & 0.14 & 220 & 0.68 & 16 & 0.029 & 490 & 0.3125 \\
\hline 215500 & 539 & 0.33 & 160 & 0.56 & 11 & 0.078 & 1020 & 1.0 \\
\hline 245275 & 740 & 0.39 & 190 & 0.50 & 10 & 0.053 & 510 & 1.25 \\
\hline \multicolumn{9}{|l|}{ W51e2 } \\
\hline 81041 & 113 & 0.04 & 95 & 0.79 & 30 & 0.012 & 490 & 0.3125 \\
\hline 91626 & 116 & - & 60 & 0.77 & 26 & 0.012 & 490 & 0.3125 \\
\hline 96371 & 119 & 0.07 & 95 & 0.77 & 25 & 0.013 & 490 & 0.3125 \\
\hline 107650 & 223 & 0.14 & 52 & 0.75 & 22 & 0.018 & 490 & 0.3125 \\
\hline 131372 & 179 & - & 60 & 0.71 & 18 & 0.019 & 490 & 0.3125 \\
\hline 150750 & 249 & 0.26 & 215 & 0.68 & 16 & 0.020 & 490 & 0.3125 \\
\hline 215500 & 221 & 0.415 & 195 & 0.56 & 11 & 0.063 & 1020 & 1.0 \\
\hline 217900 & 301 & 0.634 & 112 & 0.55 & 11 & 0.044 & 1020 & 1.0 \\
\hline 245260 & 371 & 0.75 & 75 & 0.50 & 10 & 0.051 & 510 & 1.25 \\
\hline 252227 & 384 & 0.51 & 95 & 0.48 & 10 & 0.062 & 510 & 1.25 \\
\hline 253300 & 330 & - & 85 & 0.48 & 10 & 0.045 & 510 & 1.25 \\
\hline
\end{tabular}

${ }^{a}$ Average system temperature.

${ }^{b} T_{A}^{*}=\rho T_{\mathrm{mb}}$. 